\title{
Acute and Chronic Toxicity of Carbamazepine on the Release of Chitobiase, Molting, and Reproduction in Daphnia similis
}

\author{
Huihui Chen, Xiaohong Gu *, Qingfei Zeng and Zhigang Mao
}

State Key Laboratory of Lake Science and Environment, Nanjing Institute of Geography and Limnology, Chinese Academy of Sciences, Nanjing 210008, China; hhchen@niglas.ac.cn (H.C.); qfzeng@niglas.ac.cn (Q.Z.); zgmao@niglas.ac.cn (Z.M.)

* Correspondence: xhgu@niglas.ac.cn; Tel.: +86-025-8688-2006

Received: 6 November 2018; Accepted: 10 January 2019; Published: 13 January 2019

\begin{abstract}
As one of the most frequently detected pharmaceutical compounds in aquatic environments, carbamazepine (CBZ) has recently been shown to cause acute and chronic toxicity in a variety of non-target aquatic organisms. However, little is known about the ecotoxicological effects it has on the molting and reproduction of crustaceans. The aim of the present work was to evaluate the acute and chronic toxic responses to CBZ in the crustacean Daphnia similis. After acute exposure (4 days), CBZ did not cause lethal toxicity at the tested concentrations. However, CBZ did inhibit the molting and release of chitobiase at concentrations higher than $6.25 \mu \mathrm{g} / \mathrm{L}$, with $96 \mathrm{~h} \mathrm{EC}_{50}$ (median effective concentration) values of 864.38 and $306.17 \mu \mathrm{g} / \mathrm{L}$, respectively. The results of chronic exposure showed that the mean number of molts, size of the first brood, mean number of offspring per brood, mean number of broods per female, and total offspring per female decreased significantly with increasing CBZ concentrations. Significant effects of CBZ on the molting or fecundity in D. similis were observed even at concentrations as low as $0.03 \mu \mathrm{g} / \mathrm{L}$. In conclusion, CBZ can cause inhibition of molting, delayed reproduction, and reduced fecundity in D. similis. CBZ toxicity to D. similis depends on the timing and duration of the exposure. Moreover, our results indicated that CBZ would act as an endocrine disrupter in D. similis, as with vertebrates (e.g., fish).
\end{abstract}

Keywords: carbamazepine; molting; Daphnia similis; chitobiase; chronic toxicity; reproduction

\section{Introduction}

In recent years, with advances in environmental analysis technology, a new class of environmental pollutants (pharmaceuticals and personal care products (PPCPs)) has begun to receive widespread attention [1,2]. Most PPCPs in the environment have low concentrations, complex structures, and difficult degradation and accumulation characteristics [3]. Although the concentrations are low in the environment, long-term pollution of PPCPs may cause endocrine disruption or reproductive toxicity to aquatic organisms, induce changes in biochemical functions of aquatic habitats, and do great harm to the environment [4-10]. Carbamazepine (CBZ), a heavily used pharmaceutical, is mainly employed for the treatment of epilepsy, arrhythmia, depression, and other diseases [6]. CBZ is discharged into the environment in a variety of ways, and can be residual in the environment, resulting in its persistence in water bodies and adverse effects on ecosystems [9]. CBZ contamination has been found in $\mathrm{ng} / \mathrm{L}$ to $\mu \mathrm{g} / \mathrm{L}$ concentrations in sewage influent and effluent water, surface water, and even drinking water [11-15]. For example, the concentration range of CBZ in the Shanghai sewage treatment plant was 230-1110 ng/L, and the maximum concentration in the Yangtze River was $1090 \mathrm{ng} / \mathrm{L}$ [11]. Liu et al. [13] also found that the detection rate of CBZ in the rivers in Nanjing was 100\%, with a 
concentration range of $0.2-6.9 \mathrm{ng} / \mathrm{L}$ in the water, and $0.05-1.6 \mathrm{ng} / \mathrm{g}$ in the bodies of fish. In a recent study conducted at Taihu Lake, China, CBZ was the most frequently detected compound, with a detection rate of $100 \%$ in water, with concentrations ranging from 0.24 to $8.74 \mathrm{ng} / \mathrm{L}$, and a $32 \%$ detection rate in biotic samples, including common carp (Cyprinus carpio), yellow catfish (Pelteobagrus fulvidraco), and crucian carp (Carassius auratus) [14].

Due to its high concentrations in aquatic environments, CBZ has received growing attention as an emerging contaminant based on its potential threat to non-target species [15-18]. For example, Malarvizhi et al. [15] reported that the median lethal concentration ( $\left.\mathrm{LC}_{50}\right)$ of $\mathrm{CBZ}$ to the common carp (Cyprinus carpio) for $24 \mathrm{~h}$ was $59.70 \mathrm{mg} / \mathrm{L}$, and CBZ induced alterations in the activities of glutamate oxaloacetate transaminase (GOT), glutamate pyruvate transaminase (GPT), and lactate dehydrogenase (LDH) in various organs. Aguirre-Martínez et al. [17] also reported that CBZ had significant effects on stable lysosome membrane, dibenzyl fluorescent dehydrogenase, glutathione S-transferase, glutathione peroxidase, lipid peroxidation, and DNA adducts of the common crab C. carpio. In addition, exposure to environmentally relevant concentrations of CBZ altered the siphoning behavior, biomarkers, $h s p$ mRNA levels, and protein levels in the gills and digestive gland of the Asian clam (Corbicula fluminea). The changes in the biomarkers suggest that the effect of CBZ is related to oxidative stress [6]. Therefore, research into the toxic effects of $\mathrm{CBZ}$ on aquatic organisms should not be neglected. Concerning crustaceans, the existing knowledge about the toxic effects of $\mathrm{CBZ}$ is limited to the model species (e.g., Daphnia magna) $[19,20]$. For example, $1 \mu \mathrm{g} / \mathrm{L} \mathrm{CBZ} \mathrm{can} \mathrm{enhance} \mathrm{reproduction} \mathrm{and} \mathrm{increases}$ positive phototactic behavior in D. magna [19]. Kovacevic et al. [20] also reported that aromatic amino acids, including serine, glycine, and alanine, are potential bioindicators for sub-lethal CBZ exposure that may have altered energy metabolism. Molting is a natural biological process in arthropods, including crustaceans. During molting, the animal generates a new exoskeleton and sheds the old one to grow and develop [21]. In terms of endocrine-disrupting effects, molting is used as an effective biomarker to assess the toxicity of contaminants in crustaceans. Previous studies have reported that various xenobiotics (such as polychlorinated biphenyls, perfluorooctane sulfonate, pesticides, and heavy metals) can affect molting in crustaceans by disrupting molting hormone signaling, including chitinolytic enzyme, 20-hydroxyecdysone, and molting hormone signaling genes [22-26]; however, as a neuro-active pharmaceutical, and a potential endocrine disruptor in fish [10], neither the effects of CBZ on molting in crustaceans nor the underlying mechanisms are well studied or understood.

Thus, the aim of the current study was to determine the acute and chronic effect of CBZ on the molting, growth, and reproduction of Daphnia similis, which is a main crustacean species in Lake Taihu, China. As described above, CBZ is one of the most frequently detected pharmaceuticals in Lake Taihu, China $[12,14]$, however, the potential toxicity of CBZ to D. similis is unknown. In the present study, newborn $D$. similis ( $<24 \mathrm{~h}$ old) were exposed to environmentally relevant concentrations of CBZ to investigate the effects of acute (4 days) and chronic (21 days) exposures on the survival, molting, growth, and reproduction of this species. After the acute exposure, the survival, number of molts, and chitobiase activity were measured. Chitobiase, a major chitinolytic enzyme in the molting fluid, is required for complete degradation of the old exoskeleton [21]. Based on the toxicological findings, we discuss the possible mechanism of CBZ action on molting and reproduction in this crustacean species.

\section{Materials and Methods}

\subsection{Chemicals}

CBZ (CAS: 298-46-4, purity > 97\%, Figure 1) and dimethylsulfoxide (DMSO) was purchased from Aladdin Industrial Corporation (Shanghai, China). A CBZ stock solution $(10 \mathrm{mg} / \mathrm{mL})$ was prepared in DMSO and stored in brown bottles. CBZ stock solution was made anew every week. 


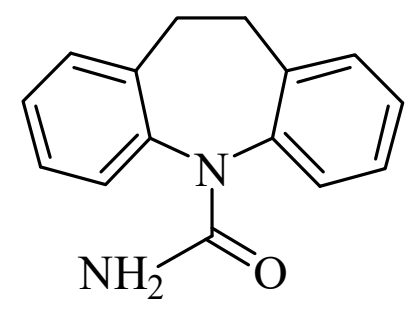

Figure 1. The structure of carbamazepine.

\subsection{Test Organism}

D. similis organisms were isolated from Lake Taihu (Wuxi, Jiangsu, China) and had been cultured and maintained in our laboratory for one year. The animals were cultured in 200-mL beakers at $20 \pm 1{ }^{\circ} \mathrm{C}$ under a light-dark period of $16: 8 \mathrm{~h}$ and fed with green algae (Scenedesmus obliquus; $10^{6}$ cells $/ \mathrm{mL}$ ) according to the Organization for Economic Cooperation (OECD) test guidelines 202 and $211[27,28]$. The green algae S. obliquus was cultured axenically in a liquid M4 medium [27], under the same conditions as the animals. Newborn D. similis ( $<24 \mathrm{~h}$ old) were used in the experiment for the acute and chronic exposure.

\subsection{Experimental Design}

\subsubsection{Acute Exposure}

The acute toxicity tests (4 days) were performed following the OECD test guideline 202 [27]. In accordance with the results of previous literature [19,20], six nominal concentrations of CBZ treatments $(6.25,12.5,25,50,100$, and $200 \mu \mathrm{g} / \mathrm{L}$ ) and a solvent control (treated with $0.01 \% \mathrm{DMSO}$ ) of the experimental solution $(100 \mathrm{~mL}$ ) were prepared in $125-\mathrm{mL}$ glass beakers. Ten experimental animals were placed randomly in each of the beakers. Each treatment was made up of three replicates. The experimental conditions were identical to those used during culturing. To keep the CBZ concentrations constant, the test medium in each beaker was renewed daily. The test animals were fed daily with S. obliquus to avoid potential stress from starvation. Molting was examined by counting shed carapaces. Survival and molting frequency (number of molts) were recorded daily. The shed carapaces and immobile animals were removed after observation to avoid the potential aggregation of microorganisms in the exposure medium. The exposure medium $(50 \mathrm{~mL})$ was sampled before renewing the exposure medium every day and stored at $4{ }^{\circ} \mathrm{C}$ prior to chitobiase analysis.

\subsubsection{Chronic Exposure}

Chronic toxicity tests (21 days) were performed following the OECD test guideline 211 [28]. Test concentrations for chronic exposure were selected based on the $96 \mathrm{~h} \mathrm{EC} 50$ (median effective concentration) obtained from the acute toxicity tests. The test animals were exposed to four nominal CBZ concentrations $\left(0.03,0.3,3\right.$, and $30 \mu \mathrm{g} / \mathrm{L}\left(10 \%\right.$ of the $96 \mathrm{~h} \mathrm{EC}_{50}$ of chitobiase $\left.)\right)$, and treatment with $0.01 \%$ DMSO was used as a solvent control. One experimental animal ( $<24$-h-old newborn) was placed randomly in each of the $125-\mathrm{mL}$ glass beakers (contained $100 \mathrm{~mL}$ experimental solution). Each treatment was made up of six replicates. The water and CBZ or DMSO was refreshed daily. The experimental conditions were identical to those used during culturing. The duration of the experiment was 21 days, during which survival and molting were monitored daily. Dead individuals were confirmed under a microscope and then removed. Molting was examined by counting shed carapaces [23]. Offspring production was measured daily; once counted, the offspring were removed. The physiological parameters, including the number of molts, the time to first brood of the females, the size of first brood of females, the mean number of broods per female, the number of offspring in each brood, and the total number of offspring per female were recorded to evaluate the toxicity of CBZ on the reproduction in $D$. similis. 
During the 21 days of chronic exposure, the number of immobile adults, newborns, and shed carapaces were counted and removed daily. For body length measurements, after the first brood of the females, the surviving individuals were collected separately with a pipette and transferred into a polystyrene cup. Here, they were briefly deposited into a drop of exposure medium and photographed using a CCD (Charge-Coupled Device) (DS-Fi2, Nikon, Tokyo, Japan) fitted to a binocular dissecting microscope (Eclipse Ni, Nikon, Japan) [24]. Surviving adults were then reintroduced into the beakers and fed with green microalgae. Body length was measured on the pictures from the eye to the base of the tail spin using an image analysis software (NIS-elements, Nikon, Tokyo, Japan) [29].

\subsection{CBZ Quantification}

CBZ concentrations were quantified using ultra-performance liquid chromatography tandem mass spectrometry (UPLC-MS/MS; Waters Corporation, Milford, MA, USA) according to a previously described method $[6,30]$ in the analysis and testing center of Nanjing Institute of Geography and Limnology, Chinese Academy of Sciences. Since the test medium in each beaker was renewed daily, CBZ concentrations were quantified immediately after the beakers were dosed only at the first day of the exposure. Briefly, water samples were filtered through a 0.22- $\mu \mathrm{m}$ GH Polypro membrane filter (PALL, New York, NY USA) to remove any suspended matter and injected into a Waters Acquity UPLC fitted with a BEH C18 column $(50 \times 2.1 \mathrm{~mm}, 1.7 \mu \mathrm{m}$; Waters, Milford, MA, USA) maintained at $30{ }^{\circ} \mathrm{C}$. A tandem Quattro Premier XEV TQD mass spectrometer (Waters, Milford, MA, USA) equipped with an electrospray ionization (ESI) ion source was used for CBZ detection, with all measurements taken in positive ESI mode. The multiple reaction monitoring (MRM) transitions were 237.1 > 194.2 and 237.1 > 179.2 for quantification and confirmation, respectively. The limit of quantification (LOQ) of the method was $0.02 \mathrm{ng} / \mathrm{L}$. The CBZ concentrations determined in all treatments are shown in Table 1 . The nominal CBZ values are used throughout the remaining text.

Table 1. Carbamazepine (CBZ) concentration (mean $\pm S D$ ) measured in the water of the acute and chronic exposure experiment.

\begin{tabular}{cccc}
\hline Exposure & Treatments & NC $^{\mathbf{1}}(\mu \mathrm{g} / \mathrm{L})$ & MC $^{\mathbf{2}}(\mu \mathrm{g} / \mathrm{L})$ \\
\hline & Solvent Control & 0 & $<\mathrm{LOQ}^{3}$ \\
& $6.25 \mu \mathrm{g} / \mathrm{L}$ & 6.25 & $6.25 \pm 0.05$ \\
Acute exposure & $12.5 \mu \mathrm{g} / \mathrm{L}$ & 12.5 & $12.62 \pm 0.21$ \\
& $25 \mu \mathrm{g} / \mathrm{L}$ & 25 & $25.68 \pm 0.15$ \\
& $50 \mu \mathrm{g} / \mathrm{L}$ & 50 & $50.26 \pm 1.25$ \\
& $100 \mu \mathrm{g} / \mathrm{L}$ & 100 & $100.89 \pm 2.63$ \\
& $200 \mu \mathrm{g} / \mathrm{L}$ & 200 & $203.40 \pm 2.59$ \\
Chronic exposure & Solvent Control & 0 & $<\mathrm{LOQ}^{3}$ \\
& $0.03 \mu \mathrm{g} / \mathrm{L}$ & 0.03 & $0.03 \pm 0.01$ \\
& $0.3 \mu \mathrm{g} / \mathrm{L}$ & 0.3 & $0.30 \pm 0.06$ \\
& $3 \mu \mathrm{g} / \mathrm{L}$ & 3 & $3.02 \pm 0.53$ \\
& $30 \mu \mathrm{g} / \mathrm{L}$ & 30 & $31.86 \pm 0.88$ \\
\hline
\end{tabular}

${ }^{1}$ Nominal Concentrations; ${ }^{2}$ Measured Concentrations; ${ }^{3}$ Limit of Quantification.

\subsection{Measurement of Chitobiase Activity}

During the acute exposure, the activities of the release of chitobiase into the water were measured using a commercial kit (Jiancheng, Nanjing, China) according to the manufacturer's protocol. The chitobiase kit used $p$-nitrophenyl-glucoside as the reaction substrate. When hydrolyzed by $\mathrm{N}$-acetyl-beta-glucosaminidase (NAG), p-nitrophenol was generated from the substrate. Reactions were conducted at $37^{\circ} \mathrm{C}$ for $15 \mathrm{~min}$ and stopped by the addition of sodium carbonate. Absorbances of the reaction mixtures were read at $400 \mathrm{~nm}$ using a spectrophotometer. One unit of chitobiase activity was defined as $1 \mu \mathrm{mol}$ of $p$-nitrophenol generated per min at $37^{\circ} \mathrm{C}$. 


\subsection{Statistical Analysis}

All statistical analyses were performed using SPSS software (version 16.0; SPSS, Chicago, IL, USA) and OriginPro (version 16.0; OriginLab, Northampton, MA, USA) software. The $\mathrm{EC}_{50}$ values were calculated by SPSS software based on the probit method. Quantitative data were expressed as mean \pm standard error of the mean (SEM) in the acute exposure, and the mean \pm standard deviation $(S D)$ in the chronic exposure. The significance of the differences between the exposed and control samples was determined using a one-way ANOVA $(p<0.05)$ followed by Dunnett's test for multiple comparisons.

\section{Results}

\subsection{Acute Toxicity}

\subsubsection{Acute Toxicity of CBZ on the Molting in D. similis}

Over the course of the 4 days acute exposure to various CBZ concentrations, less than $3 \%$ mortality was observed at all CBZ concentrations (data not shown) and exposure to lower concentrations of CBZ did not result in any lethality. The results showed that the acute effect of CBZ on D. similis was not detected in the current exposure concentration levels. The effect of CBZ on molting frequency of $D$. similis was not concentration-dependent for all the concentrations tested (Figure 2a), with $200 \mu \mathrm{g} / \mathrm{L}$ significantly reducing molting after 48,72 , and $96 \mathrm{~h}$. No marked change in molting frequency was detected after $24 \mathrm{~h}$ exposure or at concentrations lower than $6.25 \mu \mathrm{g} / \mathrm{L}$. Based upon the concentration-response curves (Figure 2) and calculated using the SPSS software based on the probit method, the estimated $\mathrm{EC}_{50}$ of CBZ for survival were $864.38 \mu \mathrm{g} / \mathrm{L}$ (96 h) (Table 2).
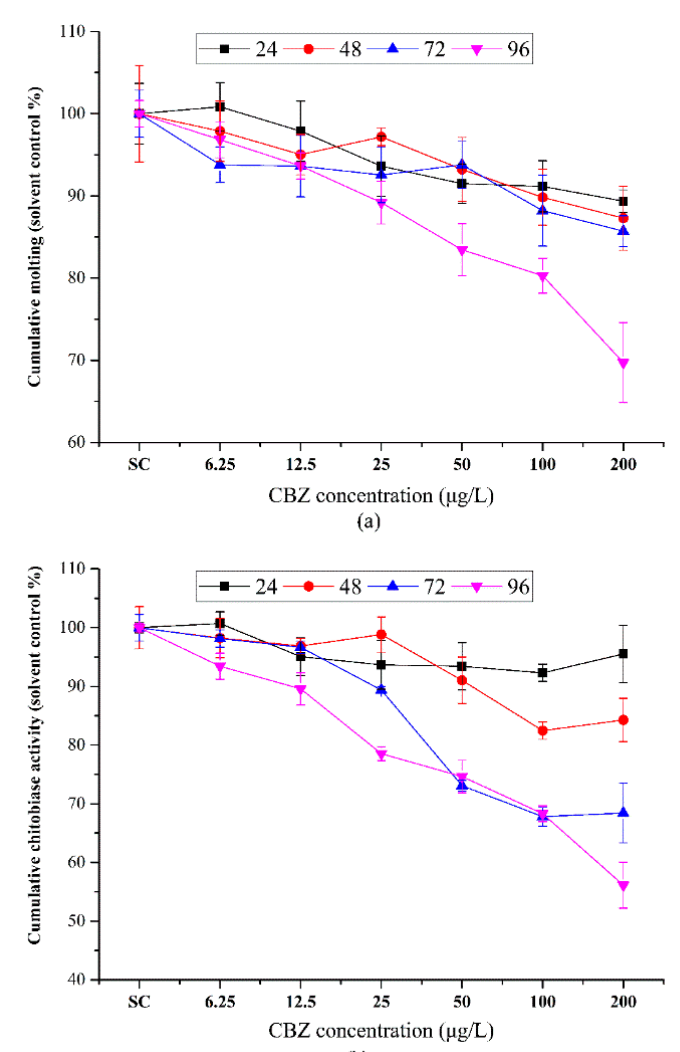

(b)

Figure 2. Effects of carbamazepine on cumulative molting (a) and chitobiase release (b) in juvenile Daphnia similis during acute exposure. Results are presented as mean $\pm S E M, n=3$ (10 individuals in each replicate). 


\subsubsection{Acute Toxicity of CBZ on the Chitobiase in D. similis}

Results from the acute toxicity test showed that the effect of $C B Z$ on the release of chitobiase in D. similis was also concentration-dependent, with exposure to $100 \mu \mathrm{g} / \mathrm{L} \mathrm{CBZ} \mathrm{significantly} \mathrm{reducing}$ the release of chitobiase after 48,72 , and $96 \mathrm{~h}$ of exposure (Figure $2 \mathrm{~b}$ ). The estimated $\mathrm{EC}_{50}$ values of CBZ for the release of chitobiase were $3985.24 \mu \mathrm{g} / \mathrm{L}$ (48 h), 345.58 (72 h), and $306.17 \mu \mathrm{g} / \mathrm{L}$ (96 h). A summary of the estimated effect concentrations for different endpoints is presented in Table 2.

Table 2. Summary of the effect concentrations $(\mu \mathrm{g} / \mathrm{L})$ of carbamazepine for different endpoints in juvenile Daphnia similis during acute exposure.

\begin{tabular}{ccccccc}
\hline \multirow{2}{*}{ Time } & \multicolumn{5}{c}{ Endpoint } \\
\cline { 2 - 7 } & \multicolumn{7}{c}{ Molting } & \multicolumn{5}{c}{ Chitobiase } \\
\cline { 2 - 7 } & NOEC $^{1}$ & LOEC $^{2}$ & EC $_{50}{ }^{3}$ & NOEC & LOEC & EC $_{50}{ }^{3}$ \\
\hline $24 \mathrm{~h}$ & 200 & $>200$ & $/{ }^{4}$ & 200 & $>200$ & $/^{4}$ \\
\hline $48 \mathrm{~h}$ & 100 & 200 & $/ 4$ & 50 & 100 & $3985.24^{5}$ \\
\hline $72 \mathrm{~h}$ & 100 & 200 & $/{ }^{4}$ & 12.5 & 25 & $345.58^{5}$ \\
\hline $96 \mathrm{~h}$ & 12.5 & 25 & $864.38^{5}$ & $<6.25$ & 6.25 & $306.17^{5}$ \\
\hline
\end{tabular}

${ }^{1}$ No Observed Effect Concentration; ${ }^{2}$ Lowest Observed Effect Concentration; ${ }^{3}$ Median Effective Concentrations;

${ }^{4}$ No values were calculated based on the probit method; ${ }^{5}$ Predicted values, observed effect less than $50 \%$.

\subsection{Chronic Toxicity}

\subsubsection{Survival and Molting}

Over the course of the 21 days of exposure to various CBZ concentrations, less than $2 \%$ mortality was observed at all CBZ concentrations (data not shown). However, CBZ significantly $(p<0.05)$ affected the molting of $D$. similis at CBZ concentrations higher than $3 \mu \mathrm{g} / \mathrm{L}$ (Figure 3a). The mean number of molts of individual daphnids in the solvent control group was $15.50 \pm 1.38$. Whereas, the mean number of molts for individual daphnids at 3 and $30 \mu \mathrm{g} / \mathrm{L} \mathrm{CBZ} \mathrm{was} 10.17 \pm 0.75$ and $6.83 \pm 0.75$, respectively, which were both significantly decreased compared to the control group $(p<0.05$; Figure 3a).

\subsubsection{Age and Body Size of First Brood}

The time to first brood of the females and the size of first brood of females were also measured during the chronic exposure as the two variables of development used to evaluate the effects of CBZ on development in D. similis. In the solvent control group, the mean time to first brood of the females was $7.67 \pm 1.03$ days; no significantly inhibition was observed at the CBZ treated groups $((p>0.05$; Figure $3 b)$. On the other hand, another variable of development, the size of first brood of females, was significantly reduced by CBZ only at the highest concentration $(30 \mu \mathrm{g} / \mathrm{L})(p<0.05$; Figure 3c).

\subsubsection{Fecundity}

The toxicity of CBZ on the fecundity was evaluated by measuring the mean number of broods per female, the number of offspring in each brood, and the total number of offspring per female throughout the chronic period. These three physiological parameters all decreased with increased CBZ exposure. The mean number of offspring per brood was more sensitive than the other two, with significant inhibition detected at all four of the CBZ exposure groups $(p<0.05$; Figure $3 \mathrm{~d})$. The number of offspring in each brood and the total number of offspring per female were similar, both significantly inhibited only at the CBZ concentrations of 3 and $30 \mu \mathrm{g} / \mathrm{L}$ groups $(p<0.05$; Figure $3 \mathrm{c}, \mathrm{d})$. 


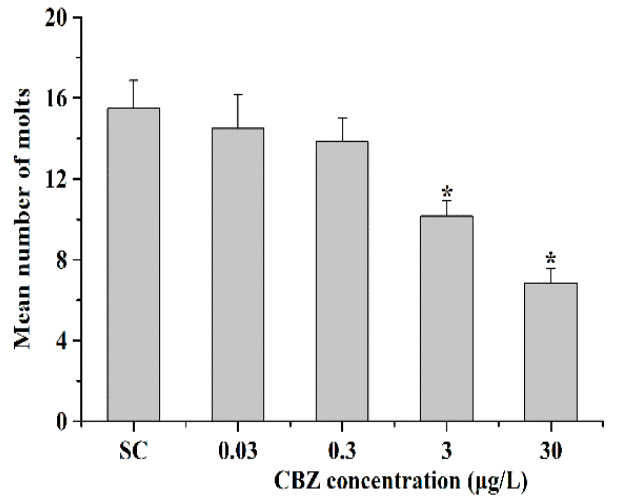

(a)

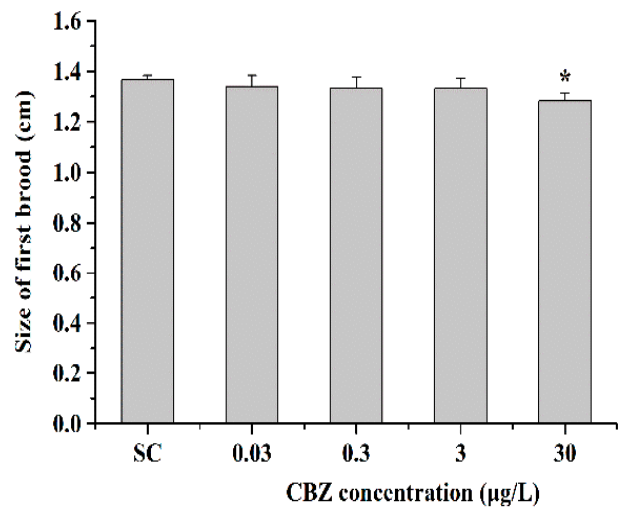

(c)

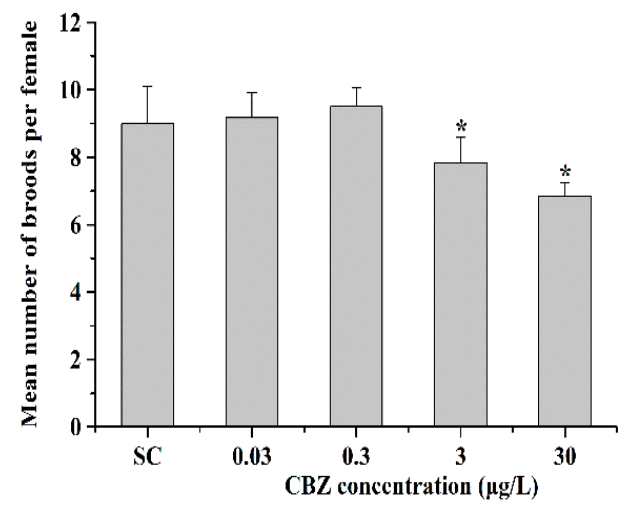

(e)

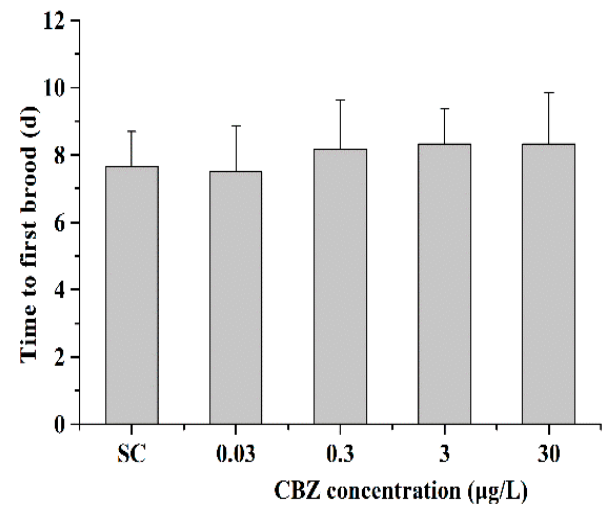

(b)

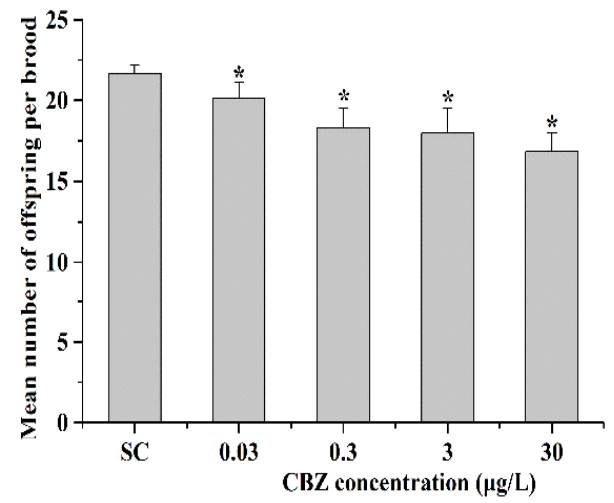

(d)

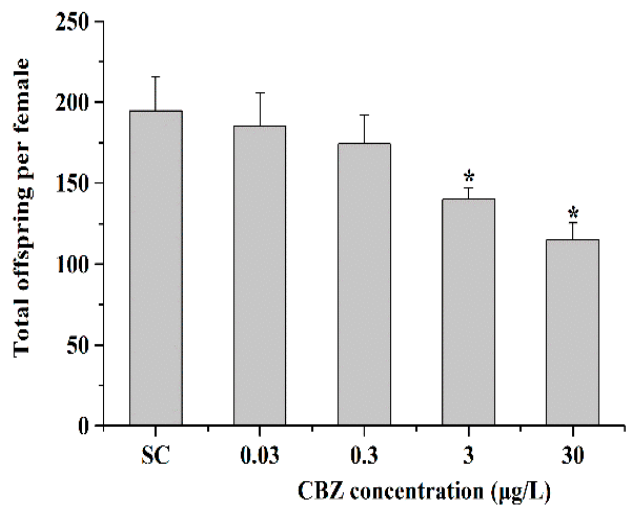

(f)

Figure 3. The individual endpoint measurements after the chronic exposure (21 d). (a) Mean number of molts; (b) Time to first brood (days); (c) Size of the first brood (cm); (d) Mean number of offspring per brood; (e) Mean number of broods per female; (f) Total offspring per female. Results are presented as mean $\pm S D, N=6{ }^{*} p<0.05$.

\section{Discussion}

Daphnia spp., an ecologically important group of model species with short life cycles, strong reproductive abilities, and sensitivity to their chemical environment, has been widely used in aquatic toxicology bioassays for many years [23,31]. Moreover, Daphnia play a critical role in aquatic food webs by serving as an intermediate between primary producers and fish; as such, life history changes in Daphnia could trigger community- or ecosystem-level responses [31]. In the present study, the small crustacean $D$. similis was used as a model organism to evaluate the acute and chronic toxicity of the pharmaceutical CBZ on the molting and reproduction in crustaceans. D. similis was selected because it has a critical role in the freshwater ecosystems of Lake Taihu, China, and has a similar body size with 
the common model organism D. magna. D. similis have also been used in field and laboratory studies to measure environmental perturbations or contaminations [24]. Many of the $\mathrm{EC}_{50}$ values shown in Table 2 are predicted values, because effects of less than $50 \%$ were observed during the acute exposure. Since the standard exposure method and statistical approaches of OECD test guidelines were used, the results are reliable.

\subsection{Effect of CBZ on the Survival and Molting in D. Similis}

After acute exposure to CBZ, no effect was observed on the survival of $D$. similis. It seems that CBZ did not cause acute lethal effects in D. similis. Similar to our study, the conclusions of various studies suggested that environmental pharmaceuticals do not cause acute toxic effects [32-34]. For example, the $48 \mathrm{~h} \mathrm{EC}_{50}$ value for D. magna was $>13,800 \mu \mathrm{g} / \mathrm{L}$ [33], however, Kim et al. [34] reported that the acute $\mathrm{EC}_{50}$ values of CBZ for the same species was $>100 \mathrm{mg} / \mathrm{L}$ for $48 \mathrm{~h}$ and $76.3 \mathrm{mg} / \mathrm{L}$ for $96 \mathrm{~h}$ [34], whereas over the course of the 21 days exposure to various CBZ concentrations, less than $2 \%$ mortality was observed at all CBZ concentrations. The results showed that even the highest concentration of $30 \mu \mathrm{g} / \mathrm{L}$ ( $10 \%$ of the $96 \mathrm{~h} \mathrm{EC}_{50}$ of chitobiase) was also too low to be lethal. Thus, chronic exposure studies with more specific endpoints other than survival should be used in CBZ risk assessment in daphnids [6,33].

Molting in crustaceans is an important biological process for growth, development, and reproduction [35]. However, to our knowledge, studies involving the toxicity of CBZ on molting in crustaceans is limited. The molting of $D$. similis can be inhibited by many environmental contaminants, such as ammonia and nitrite, as well as hypoxia $[23,24]$. These subtle, sublethal effects on the normal life processes of Daphnia often occur at concentrations that are several orders of magnitude lower than lethal concentrations. It seems that molting was more sensitive than immobility, thus it would be a good endpoint to detect the acute toxicity of CBZ in crustaceans. Moreover, the chronic exposure also proved the sensitivity of molting. CBZ significantly affected the molting of $D$. similis at CBZ concentrations higher than $3 \mu \mathrm{g} / \mathrm{L}$ after the 21 days of chronic exposure. Although $3 \mu \mathrm{g} / \mathrm{L}$ is just a little higher than the concentration at which CBZ is found in the environment, more attention should be paid to molting rather than survival when CBZ toxicity is considered.

\subsection{Toxicity of CBZ on the Release of Chitobiase in D. Similis}

In the process of molting, arthropods living in water will release chitobiase-rich peeling liquid into water. The larger the number and size of the aquatic arthropods, the higher the release of chitobiase in vitro [36]. Therefore, theoretically, chitobiase can be a prerequisite for biomass indicators of aquatic arthropods. The relationship between chitobiase release in vitro and the biomass of aquatic arthropods has been confirmed in some laboratory experiments [21]; the results of field investigations also confirm the existence of this relationship to some extent [37]. In the current study, after acute exposure to CBZ, the release of chitobiase in $D$. similis was concentration-dependent during the 4-day exposure period. Compared with the control, CBZ significantly reduced the release of chitobiase. Moreover, with the decrease in chitobiase, molting of $D$. similis was also inhibited. This shows that chitobiase activity should be an indicator of altered growth and reproduction in D. similis exposed to CBZ. Similar results were also reported by Duchet et al.; after exposed to spinosad and diflubenzuron, the chitobiase activity acted as an indicator of altered survival, growth, and reproduction in Daphnia pulex and D. magna [38].

\subsection{Chronic Toxicity of CBZ on the Reproduction in D. similis}

Previous studies have suggested that CBZ could act as an endocrine disruptor in Daphnia, as it decreases their reproductive output and causes developmental abnormalities in their offspring [19]. Therefore, the chronic toxicity of CBZ on the reproduction in D. similis was tested in the current study. As described above, the chitobiase activity is an indicator of altered reproduction in Daphnia [38], so $10 \%$ of the $96 \mathrm{~h} \mathrm{EC}_{50}$ of chitobiase was referred to for selecting the concentrations of the chronic exposure. After chronic exposure, the endpoints showed that the reproduction of $D$. similis was 
significantly inhibited by CBZ. Chronic exposure to CBZ resulted in smaller size of the first brood of the females, reduced fecundity (the mean number of broods per female, the number of offspring in each brood, and the total number of offspring per female). These subtle, sublethal effects on the normal life processes of Daphnia often occur at concentrations that are several orders of magnitude lower than the lethal concentrations [39]. For example, Oropesa et al. showed that chronic exposure to CBZ significantly decreased the reproductive output and number of $D$. magna at $200 \mu \mathrm{g} / \mathrm{L}$ [40], which was similar to our result. A previous study reported that aromatic amino acids, including serine, glycine, and alanine, of D. magna were potential bioindicators for sub-lethal CBZ exposure that may have altered their metabolism [20]. Therefore, the alteration of energy metabolism in D. similis by CBZ may lead to the changes in the molting and reproduction. On the other hand, opposite results were reported by Rivetti et al., who showed that, as a neuro-active pharmaceutical, CBZ was able to enhance reproduction at $1 \mu \mathrm{g} / \mathrm{L}$ of CBZ [19]. The different results may be due to the higher concentrations used in the current study. To resolve this, further research should be conducted using a wide range of concentrations.

The results of the chronic exposure together with the acute exposure suggested that CBZ acts as an endocrine disruptor in $D$. similis. Further, when comparing the effect concentrations of CBZ between different endpoints among the acute and chronic exposures, the release of chitobiase was identified to be the most sensitive endpoint in response to CBZ. The LOEC obtained from the current study suggested that chitobiase was the most sensitive indicator of changes to CBZ. The expression of chitobiase is positively regulated by the endogenous molting hormone 20-hydroxyecdysone through transcriptional activation of the ecdysone receptor (EcR) [22,41]. Even it is still not clear how release of chitobiase correlates with the molting [21], the results of the current study suggest that CBZ acts as an EcR agonist in D. similis. Future relevant toxicity tests, especially chronic toxicity tests with multiple endpoints, such as chitobiase mRNA, are expected to enrich the toxicity test database of the toxicity of CBZ in Daphnia.

\section{Conclusions}

In the present study, we evaluated the acute and chronic aquatic toxicity of the most frequently detected pharmaceutical compound (CBZ) in aquatic environments, at environmentally relevant concentrations, using the model organism $D$. similis. The acute toxicity results showed that CBZ did not cause lethal toxicity at the tested concentrations. However, significant effects of CBZ on the molting and fecundity in D. similis were observed even at concentrations as low as $0.03 \mu \mathrm{g} / \mathrm{L}$. Our results show that CBZ toxicity to $D$. similis depends on the timing and duration of the exposure. In conclusion, CBZ can cause inhibition of molting, delayed reproduction, and reduced fecundity in D. similis. Moreover, since the release of chitobiase is an indicator of potential molting and reproductive disruption, CBZ acts as an endocrine disruptor in D. similis, as with vertebrates (e.g., fish). It is expected that CBZ exposure may lead to a broad range of developmental and reproductive endpoints in invertebrate populations, and thus further research on the ecological impacts of CBZ should be conducted.

Author Contributions: H.C. and X.G. conceived and designed the investigation; H.C., Q.Z., and Z.M. performed the experiments and analyzed the data. H.C. and X.G. wrote the paper.

Acknowledgments: This work was supported by the National Key Technology R\&D program of China (No.2015BAD13B06), NIGLAS Independent Deployment (ProgramNIGLAS2018GH04), Jiangsu Provincial Aquaculture Foundation of China (No. Y2017-26), and the Water Conservancy Science and Technology Project of Jiangsu Province (No. 2017013).

Conflicts of Interest: The authors declare no conflict of interest. The founding sponsors had no role in the design of the study; in the collection, analyses, or interpretation of data; in the writing of the manuscript, and in the decision to publish the results. 


\section{References}

1. Daughton, C.G.; Ternes, T.A. Pharmaceuticals and personal care products in the environment: Agents of subtle change? Environ. Health Perspect. 1999, 107, 907-938. [CrossRef]

2. Ferrer, I.; Thurman, E.M. Analysis of 100 pharmaceuticals and their degradates in water samples by liquid chromatography/quadrupole time-of-flight mass spectrometry. J. Chromatogr. A 2012, 1259, 148-157. [CrossRef] [PubMed]

3. Liu, J.L.; Wong, M.H. Pharmaceuticals and personal care products (PPCPs): A review on environmental contamination in China. Environ. Int. 2013, 59, 208-224. [CrossRef]

4. Fent, K.; Weston, A.A.; Caminada, D. Ecotoxicology of human pharmaceuticals. Aquat. Toxicol. 2006, 2, 122-159. [CrossRef] [PubMed]

5. Daughton, C.G. The Matthew Effect and widely prescribed pharmaceuticals lacking environmental monitoring: Case study of an exposure-assessment vulnerability. Sci. Total Environ. 2014, 466, 315-325. [CrossRef]

6. Chen, H.; Zha, J.; Liang, X.; Li, J.; Wang, Z. Effects of the human antiepileptic drug carbamazepine on the behavior, biomarkers, and heat shock proteins in the Asian clam Corbicula fluminea. Aquat. Toxicol. 2014, 155, 1-8. [CrossRef] [PubMed]

7. Paz, A.; Tadmor, G.; Malchi, T.; Blotevogel, J.; Borch, T.; Polubesova, T.; Chefetz, B. Fate of carbamazepine, its metabolites, and lamotrigine in soils irrigated with reclaimed wastewater: Sorption, leaching and plant uptake. Chemosphere 2016, 160, 22-29. [CrossRef]

8. Pires, A.; Almeida, A.; Correia, J.; Calisto, V.; Schneider, R.J.; Esteves, V.I.; Soares, A.M.; Figueira, E.; Freitas, R. Long-term exposure to caffeine and carbamazepine: Impacts on the regenerative capacity of the polychaete Diopatra neapolitana. Chemosphere 2016, 146, 565-573. [CrossRef]

9. Zhang, Y.; Geissen, S.U.; Gal, C. Carbamazepine and diclofenac: Removal in wastewater treatment plants and occurrence in water bodies. Chemosphere 2008, 8, 1151-1161. [CrossRef]

10. Yan, S.; Wang, M.; Zha, J.; Zhu, L.; Li, W.; Luo, Q.; Sun, J.; Wang, Z. Environmentally relevant concentrations of carbamazepine caused endocrine-disrupting effects on nontarget organisms, Chinese Rare Minnows (Gobiocypris rarus). Environ. Sci. Technol. 2018, 2, 886-894. [CrossRef]

11. Zhou, X.F.; Dai, C.M.; Zhang, Y.L.; Surampalli, R.Y.; Zhang, T.C. A preliminary study on the occurrence and behavior of carbamazepine (CBZ) in aquatic environment of Yangtze River Delta, China. Environ. Monit. Assess. 2011, 1, 45-53. [CrossRef] [PubMed]

12. Xie, Z.; Lu, G.; Liu, J.; Yan, Z.; Ma, B.; Zhang, Z.; Chen, W. Occurrence, bioaccumulation, and trophic magnification of pharmaceutically active compounds in Taihu Lake, China. Chemosphere 2015, 138, 140-147. [CrossRef] [PubMed]

13. Liu, J.; Lu, G.; Xie, Z.; Zhang, Z.; Li, S.; Yan, Z. Occurrence, bioaccumulation and risk assessment of lipophilic pharmaceutically active compounds in the downstream rivers of sewage treatment plants. Sci. Total. Environ. 2015, 511, 54-62. [CrossRef] [PubMed]

14. Xie, Z.; Lu, G.; Yan, Z.; Liu, J.; Wang, P.; Wang, Y. Bioaccumulation and trophic transfer of pharmaceuticals in food webs from a large freshwater lake. Environ. Pollut. 2017, 222, 356-366. [CrossRef]

15. Malarvizhi, A.; Kavitha, C.; Saravanan, M.; Ramesh, M. Carbamazepine (CBZ) induced enzymatic stress in gill, liver and muscle of a common carp, Cyprinus carpio. J. King Saud Univ. Sci. 2012, 2, 179-186. [CrossRef]

16. Tsiaka, P.; Tsarpali, V.; Ntaikou, I.; Kostopoulou, M.N.; Lyberatos, G.; Dailianis, S. Carbamazepine-mediated pro-oxidant effects on the unicellular marine algal species Dunaliella tertiolecta and the hemocytes of mussel Mytilus galloprovincialis. Ecotoxicology 2013, 8, 1208-1220. [CrossRef] [PubMed]

17. Aguirre-Martínez, G.V.; Del Valls, T.A.; Martín-Díaz, M.L. Early responses measured in the brachyuran crab Carcinus maenas exposed to carbamazepine and novobiocin: Application of a 2-tier approach. Ecotoxicol. Environ. Saf. 2013, 97, 47-58. [CrossRef]

18. Hampel, M.; Bron, J.E.; Taggart, J.B.; Leaver, M.J. The antidepressant drug carbamazepine induces differential transcriptome expression in the brain of Atlantic salmon, Salmo salar. Aquat. Toxicol. 2014, 151, 114-123. [CrossRef]

19. Rivetti, C.; Campos, B.; Barata, C. Low environmental levels of neuro-active pharmaceuticals alter phototactic behaviour and reproduction in Daphnia magna. Aquat. Toxicol. 2016, 170, 289-296. [CrossRef] 
20. Kovacevic, V.; Simpson, A.J.; Simpson, M.J. 1 H NMR-based metabolomics of Daphnia magna responses after sub-lethal exposure to triclosan, carbamazepine and ibuprofen. Comp. Biochem. Physiol. Part D 2016, 19, 199-210. [CrossRef]

21. Song, Y.; Villeneuve, D.L.; Toyota, K.; Iguchi, T.; Tollefsen, K.E. Ecdysone receptor agonism leading to lethal molting disruption in arthropods: Review and adverse outcome pathway development. Environ. Sci. Technol. 2017, 8, 4142-4157. [CrossRef] [PubMed]

22. Zou, E. Impacts of xenobiotics on crustacean molting: The invisible endocrine disruption. Integr. Comp. Biol. 2005, 45, 33-38. [CrossRef] [PubMed]

23. Lyu, K.; Wang, Q.; Chen, R.; Lu, Q.; Yang, Z. Inter-specific differences in survival and reproduction of cladocerans to nitrite gradient and the ecological implications. Biochem. Syst. Ecol. 2013, 48, 151-156. [CrossRef]

24. Lyu, K.; Cao, H.; Chen, R.; Wang, Q.; Yang, Z. Combined effects of hypoxia and ammonia to Daphnia similis estimated with life-history traits. Environ. Sci. Pollut. Res. 2013, 8, 5379-5387. [CrossRef] [PubMed]

25. Luo, J.; Pei, S.; Jing, W.; Zou, E.; Wang, L. Cadmium inhibits molting of the freshwater crab Sinopotamon henanense by reducing the hemolymph ecdysteroid content and the activities of chitinase and N-acetyl-beta-glucosaminidase in the epidermis. Comp. Biochem. Physiol. C Toxicol. Pharmacol. 2015, 169, 1-6. [CrossRef] [PubMed]

26. Du, Y.; Wang, W.Q.; Pei, Z.T.; Ahmad, F.; Xu, R.R.; Zhang, Y.M.; Sun, L.W. Acute toxicity and ecological risk assessment of benzophenone-3 (BP-3) and benzophenone-4 (BP-4) in ultraviolet (UV)-Filters. Int. J. Environ. Res. Public Health 2017, 14, 1414. [CrossRef] [PubMed]

27. OECD. OECD Guideline for Testing of Chemicals No. 202, Daphnia sp. Acute Immobilisation Test; Organization for Economic Cooperation and Development: Paris, France, 2004.

28. OECD. OECD Guideline for Testing of Chemicals No. 211, Daphnia Magna Reproduction Test; Organization for Economic Cooperation and Development: Paris, France, 2012.

29. Boronat, M.D.; Miracle, M.R. Size distribution of Daphnia longispina in the vertical profile. In Cladocera: The Biology of Model Organisms; Springer: Dordrecht, The Netherlands, 1997; pp. 187-196.

30. Sun, J.; Luo, Q.; Wang, D.; Wang, Z. Occurrences of pharmaceuticals in drinking water sources of major river watersheds, China. Ecotoxicol. Environ. Saf. 2015, 117, 132-140. [CrossRef]

31. Flaherty, C.M.; Dodson, S.I. Effects of pharmaceuticals on Daphnia survival, growth, and reproduction. Chemosphere 2005, 2, 200-207. [CrossRef]

32. Jos, A.; Repetto, G.; Rios, J.C.; Hazen, M.J.; Molero, M.L.; del Peso, A.; Salguero, M.; Fernández-Freire, P.; Pérez-Martín, J.M.; Cameán, A. Ecotoxicological evaluation of carbamazepine using six different model systems with eighteen endpoints. Toxicol. In Vitro 2003, 5, 525-532. [CrossRef]

33. Ferrari, B.; Paxéus, N.; Giudice, R.L.; Pollio, A.; Garric, J. Ecotoxicological impact of pharmaceuticals found in treated wastewaters: Study of carbamazepine, clofibric acid, and diclofenac. Ecotoxicol. Environ. Saf. 2003, 3, 359-370. [CrossRef]

34. Kim, Y.; Choi, K.; Jung, J.; Park, S.; Kim, P.G.; Park, J. Aquatic toxicity of acetaminophen, carbamazepine, cimetidine, diltiazem and six major sulfonamides, and their potential ecological risks in Korea. Environ. Int. 2007, 3, 370-375. [CrossRef] [PubMed]

35. Žitňan, D.; Kim, Y.J.; Žitňanová, I.; Roller, L.; Adams, M.E. Complex steroid-peptide-receptor cascade controls insect ecdysis. Gen. Comp. Endocrinol. 2007, 1, 88-96. [CrossRef] [PubMed]

36. Sastri, A.R.; Roff, J.C. Rate of chitobiase degradation as a measure of development rate in planktonic Crustacea. Can. J. Fish. Aquat. Sci. 2000, 10, 1965-1968. [CrossRef]

37. Avila, T.R.; de Souza Machado, A.A.; Bianchini, A. Estimation of zoo-plankton secondary production in estuarine waters: Comparison between the enzymatic (chitobiase)method and mathematical models using crustaceans. J. Exp. Mar. Biol. Ecol. 2012, 416, 144-152. [CrossRef]

38. Duchet, C.; Inafuku, M.M.; Caquet, T.; Larroque, M.; Franquet, E.; Lagneau, C.; Lagadic, L. Chitobiase activity as an indicator of altered survival, growth and reproduction in Daphnia pulex and Daphnia magna (Crustacea: Cladocera) exposed to spinosad and diflubenzuron. Ecotoxicol. Environ. Saf. 2011, 4, 800-810. [CrossRef] [PubMed]

39. Dodson, S.I.; Merritt, C.M.; Shannahan, J.P.; Shults, C.M. Low exposure concentrations of atrazine increase male production in Daphnia pulicaria. Environ. Toxicol. Chem. 1999, 7, 1568-1573. [CrossRef] 
40. Oropesa, A.; Floro, A.; Palma, P. Assessment of the effects of the carbamazepine on the endogenous endocrine system of Daphnia magna. Environ. Sci. Pollut. Res. 2016, 23, 17311-17321. [CrossRef]

41. Zheng, Y.P.; Krell, P.J.; Doucet, D.; Arif, B.M.; Feng, Q.L. Cloning, expression, and localization of a moltrelated beta-N-acetylglucosaminidase in the spruce budworm, Choristoneura fumiferana. Arch. Insect Biochem. Physiol. 2008, 68, 49-59. [CrossRef] 